\title{
Carbon Dioxide Transport and Sorption Behavior in Confined Coal Cores for Enhanced Coalbed Methane and $\mathrm{CO}_{2}$ sequestration
}

\author{
Sinisha A. Jikich, ${ }^{* *}$ Robert Mc. Lendon, ${ }^{*}$ Kal Seshadri, ${ }^{* *}$ Gino Irdi, ${ }^{*}$ and Duane H. Smith* \\ * National Energy Technology Laboratory, U.S. Department of Energy \\ **National Energy Technology Laboratory/Parsons
}

\begin{abstract}
Measurements of sorption isotherms and transport properties of $\mathrm{CO}_{2}$ in coal cores are important for designing enhanced coalbed methane $/ \mathrm{CO}_{2}$ sequestration field projects. Sorption isotherms measured in the lab can provide the upper limit on the amount of $\mathrm{CO}_{2}$ that might be sorbed in these projects.
\end{abstract}

Because sequestration sites will most likely be in unmineable coals, many of the coals will be deep and under considerable lithostatic and hydrostatic pressures. These lithostatic pressures may significantly reduce the sorption capacities and/or transport rates. Consequently, we have studied apparent sorption and diffusion in a coal core under confining pressure. A core from the important bituminous coal Pittsburgh \#8 was kept under a constant, three-dimensional external stress; the sample was scanned by X-ray computer tomography (CT) before, then while it sorbed, $\mathrm{CO}_{2}$. Increases in sample density due to sorption were calculated from the CT images.

Moreover, density distributions for small volume elements inside the core were calculated and analyzed. Qualitatively, the computerized tomography showed that gas sorption advanced at different rates in different regions of the core, and that diffusion and sorption progressed slowly. The amounts of $\mathrm{CO}_{2}$ sorbed were plotted vs. position (at fixed times) and vs. time (for various locations in the sample). The resulting sorption isotherms were compared to isotherms obtained from powdered coal from the same Pittsburgh \#8 extended sample.

The results showed that for this single coal at specified times, the apparent sorption isotherms were dependent on position of the volume element in the core and the distance from the $\mathrm{CO}_{2}$ source. Also, the calculated isotherms showed that less $\mathrm{CO}_{2}$ was sorbed than by a powdered (and unconfined) sample of the coal. Changes in density distributions during the experiment were also observed. After desorption, the density distribution of calculated volume elements differed from the initial distribution, suggesting hysteresis and a possible rearrangement of coal structure due to $\mathrm{CO}_{2}$ sorption.

\section{INTRODUCTION}

In the carbon dioxide enhanced coal bed methane production/sequestration process, $\mathrm{CO}_{2}$ is injected into a coal seam to drive methane out of the bulk matrix. Carbon dioxide is sorbed by the coal ${ }^{1}$; thus $\mathrm{CO}_{2}$ injection will not only increase pressure gradients to drive methane flow, but it may also displace methane that would otherwise stay sorbed in the coal matrix, by decreasing the partial pressure of methane in the gas mixture. Because coal seams have proven to store 
large quantities of sorbed gases for geologic time, they exhibit significant potential for sequestration of carbon dioxide for the indefinite future ${ }^{2}$.

There are two important parameters to consider when evaluating future $\mathrm{ECBM} / \mathrm{CO}_{2}$ sequestration prospects: the amount of gas that the reservoir can store, and, the potential to transport large quantities throughout the reservoir.

Sorption isotherms relate the gas storage capacity of the coal as a function of pressure ${ }^{3,4}$. The information obtained from sorption isotherms can be used to predict the maximum possible volume of gas that can be stored in the coal during injection, or the amount of the gas that will be released from the coal during production.

Most of the sorption studies on coal have been done on coal powders ${ }^{5,6}$. These studies provide a relatively fast way of estimating the storage capacity of coal. However, for modeling purposes, one needs also an accurate time for the sorption equilibrium to be achieved when the sample is under the same confining pressure as in reservoir conditions ${ }^{7}$. Thus, the sorption isotherms and the rate of diffusion of $\mathrm{CO}_{2}$ in coal are important parameters for both technical and economic purposes $^{8,9}$.

Only a few researchers have attempted the measurement of $\mathrm{CO}_{2}$ sorption under confining pressure. Karakan and Okandan ${ }^{10}$ observed gas transport and storage using coal samples mounted in X-ray transparent coreholders that enabled application of confining pressure during $\mathrm{CO}_{2}$ injection. The processed images from computer tomography were correlated with SEM (scanning electron microscopy) pictures at the same location, revealing different sorption rates for various lithotypes. Later, Karacan and Mitchell ${ }^{11}$ studied the behavior of different coal microlithotypes in a 2.5-cm-diameter Pittsburgh coal sample when exposed to $\mathrm{CO}_{2}$, while under a constant effective pressure of $1.36 \mathrm{MPa}$ during gas uptake. The coal was exposed to $\mathrm{CO}_{2}$ at three different gas pressures: 1.7 $\mathrm{MPa}, 3.06 \mathrm{MPa}$, and 4.4 $\mathrm{MPa}(16.78,30.2$, and $43.42 \mathrm{~atm})$. The $\mathrm{CO}_{2}$ storage process was observed using both qualitative and quantitative X-ray computerized tomography (CT) scanning. The core was examined petrographically after exposure to $\mathrm{CO}_{2}$ to identify those microlithotypes showing different sorption behavior. Results showed that different microlithotypes react differently when exposed to high pressure $\mathrm{CO}_{2}$, displaying different sorption and rate properties. Vitrinite was found to be a swelling maceral under $\mathrm{CO}_{2}$ sorption conditions. Clay and inertinite had the highest $\mathrm{CO}_{2}$ sorption rate, whereas the gas sorption rates of vitrinite and liptinite by comparison were low.

In another investigation using a confined high-volatile bituminous Pittsburgh seam coal, Karacan ${ }^{12}$ pressurized a 2.5 -cm-diameter core that was $2.5 \mathrm{~cm}$ long with $\mathrm{CO}_{2}$ at $298 \mathrm{~K}\left(25^{\circ} \mathrm{C}\right)$ at various pressures and various confining pressures. Changes in the sorbed gas concentration in the coal and matrix properties were simultaneously investigated by means of dual-energy X-ray computed tomography. Application of this technique allowed measurement of the amount of gas sorbed in various microlithotypes, observation of changes in the coal matrix, and estimation of the kinetics of the complex heterogeneous processes. Different parts of the coal reacted differently. Vitrinite, liptinite, and clarite swelled as a result of imbibition of $\mathrm{CO}_{2}$. Clay and inertinite were compressed. Vitrinite first swelled, then after reaching a maximum volume, expelled some $\mathrm{CO}_{2}$. This was called "breathing" and was thought to be the result of rearrangement of the macromolecular structure. The largest amounts of $\mathrm{CO}_{2}$ was stored in the inertinite and clay regions, which imbibed $0.08 \mathrm{~g} \mathrm{CO}_{2}$ per gram of coal. Vitrinite adsorbed $0.06 \mathrm{~g}$ 
$\mathrm{CO}_{2}$ per gram of coal. Clay-rich sections were compressed to compensate for the swelling in vitrinite regions. In vitrinite, liptinite, and clarite regions of the coal the amount of gas sorption increased substantially, followed by a falloff where some of the sorbed gas was expelled due to rearrangement of the macromolecular network to a structure that has decreased gas solubility.

In a recent work ${ }^{13}$ amounts of sorption and diffusion rates were each measured for unconfined coal cores by means of an ambient-pressure gravimetric technique; the sorptions were compared with results obtained using computer tomography. The results showed that $\mathrm{CT}$ can provide not only qualitative measurements of spatial variations of $\mathrm{CO}_{2}$ concentrations within the core, but quantitatively accurate measurements of $\mathrm{CO}_{2}$ sorption.

In this work we present a unique sorption and desorption experiment under three-dimensional confinement of a cylindrical coal core exposed to $\mathrm{CO}_{2}$ only at one side. In this way we studied the storage capacity of coal to $\mathrm{CO}_{2}$, the rate of soption through the coal at different pressure ranges, and the sorption kinetics of two regions with different lithotypes.

\section{METHODOLOGY}

Mineral samples, such as coals, are heterogeneous and contain a spectrum of lower and higher atomic number elements. When a cylindrical core is scanned, the attenuation of the X-rays is measured, and digital images are produced. These images map the numerical values of the attenuation coefficient within a trans-axial plane (i.e., "slice") of the investigated object. The attenuations depend on the electron densities, but usually these can be directly related by means of appropriate calibrations to the conventional weight densities. If only one energy level is used, the only quantitative information obtained refers to the local value of the linear attenuation coefficient, which may be insufficient for a detailed analysis ${ }^{14}$. Consequently, a dual energy scanning technique was used during this experiment. This method, known as dual energy X-ray absorptiometry (DXA), is widely used in the medical field as a means of measuring bone mineral density. Two X-ray beams with differing energy levels are aimed at the object to be studied. In the high- energy case the Compton scattering is predominant, while in the low case energy the photoelectric absorption prevails. These two effects have a known dependence on the atomic number and electron density ${ }^{15}$.

Most medical scanner units provide X-ray attenuation data in terms of CT numbers (CTN in Hounsfield units $)^{14}$. The density of a scanned material is a linear function of the low energy [Ctlow] and high energy [Cthigh] CT numbers, as expressed by the following relationship ${ }^{16}$ :

$$
\rho=\mathrm{A}[\mathrm{CT} \text { low }]+\mathrm{B}[\mathrm{CThigh}]+\mathrm{C}
$$

The coefficients, A, B, and C can be calculated using the CT numbers for the three reference materials, by solving a system of equations with three unknowns. With these coefficients, one can calculate the density of the core under vacuum and the density of the coal after the $\mathrm{CO}_{2}$ sorption process has begun. Having the values of density at each time and pressure step, and knowing the volume and porosity of the sample, one can calculate the amount of $\mathrm{CO}_{2}$ sorption. 


\section{EXPERIMENTAL}

A sample of Pittsburgh \#8 coal was obtained from the Emerald Mine near Waynesburg, PA. A cylinder of diameter $25.0 \mathrm{~mm}$ was cored from the sample and scanned in the CT instrument for an initial examination of its density heterogeneities. This core was then cut trans-axially into two shorter cores: one for further $\mathrm{CO}_{2}$ injection and $\mathrm{CT}$ scanning experiments and another for a manometric test of $\mathrm{CO}_{2}$ sorption. The CT scans revealed no significant differences between the two cores. The core used in the manometric experiment was then powdered and its sorption of $\mathrm{CO}_{2}$ was measured at $30{ }^{\circ} \mathrm{C}$ by means of a conventional manometric technique and literature values for the $\mathrm{CO}_{2}$ density ${ }^{5}$.

Figure 1 presents a schematic of the experimental setup for the CT experiments. The core with length $25.5 \mathrm{~mm}$ was placed in the sleeve (Buna rubber) of a tri-axial aluminum coreholder. This coreholder allowed application of a radial confining pressure over the length of the core, and injection of $\mathrm{CO}_{2}$ at either (or both) ends of the core. In this experiment $\mathrm{CO}_{2}$ pressure was applied only at one end. This arrangement allowed observation of the kinetics of $\mathrm{CO}_{2}$ sorption over the entire length of the core.

Table 1.

\begin{tabular}{|l|l|l|}
\hline Reference Sample & CT number at $130 \mathrm{kV}$ & CT number at $80 \mathrm{kV}$ \\
\hline Water & -95 & 11.5 \\
\hline Fused silica & 1162 & 1755 \\
\hline Aluminum & 1780 & 2725 \\
\hline
\end{tabular}

The assembled core holder was mounted in the chucks of a modified medical CT scanner (Universal System, HG 350). The scanner is a fourth-generation medical scanner, with one rotating X-ray source and 1200 detectors, with a pixel resolution of $0.25 \mathrm{~mm}$. The core was scanned in contiguous $2 \mathrm{~mm}$ thick slices; hence each measured CT number represented a voxel of $0.25 \mathrm{~mm} \times 0.25 \mathrm{~mm} \times 2.0 \mathrm{~mm}$. Fifteen scans were taken along the axial length; these included the metallic end plugs as well as the core. However, for analysis only 11 slices were used, representing only coal. Two energy levels, $130 \mathrm{kV}$ and $80 \mathrm{KV}$ at $100 \mathrm{~mA}$ were used. The scanner was calibrated with reference materials of known density: aluminum (Al), fused Silica $\left(\mathrm{SiO}_{2}\right)$, and water $\left(\mathrm{H}_{2} \mathrm{O}\right)$. These were placed inside the coreholder.

The confining pressure was supplied from a nitrogen bottle via a pressure regulator. The pressure was kept constant without problems during various pressure steps of the experiment. That was possible due to the very large nitrogen bottle volume compared to the inner volume between the sleeve and the exterior aluminum cylinder.

The $\mathrm{CO}_{2}$ was delivered to the core from a $\mathrm{CO}_{2}$ bottle. Due to the small volume of the core, the $\mathrm{CO}_{2}$ volume in the cylinder was comparatively extremely large; hence a constant $\mathrm{CO}_{2}$ pressure was maintained at the injection port, even if there were any slow leaks in the system.

The evacuated core was initially scanned at the two energy levels, $130 \mathrm{kV}$ and $80 \mathrm{kV}$, at a confining pressure of $200 \mathrm{psig}(1.36 \mathrm{Mpa})$. In all of the following steps, the pressure differential 
between confining pressure and inlet pressure was kept constant at 200 psig. The first $\mathrm{CO}_{2}$ sorption step was performed at a $\mathrm{CO}_{2}$ injection pressure of 195 psig (hence a confining pressure of 395 psig). To measure the $\mathrm{CO}_{2}$ uptake, the core was scanned repeatedly at predetermined, frequent intervals and at each energy level. The intervals between scans were increased as the elapsed time for sorption became longer, and the scanning for the first pressure step was stopped when the change in X-ray sorption appeared to be negligible. After injection for 165 hours at 200 psig, the process was repeated at $\mathrm{CO}_{2}$ injection pressures of $325 \mathrm{psig}, 450 \mathrm{psig}$, and $600 \mathrm{psig}$, with corresponding increases in the confining pressure. The injection was continued for 392 hours at 325 psig, for 282 hours at 450 psig, and for 226 hours at 600 psig, for a total of 1065 hours of injection.

After the injection at 600 psig had been stopped, the $\mathrm{CO}_{2}$ was desorbed from the core at 400 psig (for 180 hours), 200 psig (for 144 hours), and atmospheric pressure (for 278 hours), respectively, for a total experimental time (sorption plus desorption) of 1667 hours; during desorption the same 200 psig pressure differential between the confining pressure and the $\mathrm{CO}_{2}$ outlet pressure was maintained. The temperature in the laboratory was kept approximately constant at $21{ }^{\circ} \mathrm{C}$, during all phases of the CT experiment.

The average CT number for each slice at each energy level was calculated for use in equation (1). The average (bulk) density of each slice at each time was calculated from its average CT number, equation (1), and the values of $\mathrm{A}, \mathrm{B}$, and $\mathrm{C}$ obtained from the calibration measurements. From each of these slice densities the average density of the corresponding slice under vacuum was subtracted to give the density increase of the slice due to its $\mathrm{CO}_{2}$ uptake. These sliceaverage $\mathrm{CO}_{2}$ densities (in units of mass $\mathrm{CO}_{2}$ per unit volume of slice) were converted to sliceaverage $\mathrm{CO}_{2}$ concentrations in units of mass $\mathrm{CO}_{2}$ per unit volume of slice by means of the average density of each slice as obtained from the CT measurements on the evacuated core. As a check on the accuracy of the densities determined from the CT data, the average (mass) density of the core was calculated from the $\mathrm{CT}$ data and compared to the sample density as obtained from its weight and volume.

Color images were generated that illustrated the spatial distribution of density in each slice either before or after sorption had occurred. Images also were generated that illustrated the spatial distribution of $\mathrm{CO}_{2}$ within the sample after a chosen injection time. The analyses were performed with VoxelCalc ${ }^{17} 5$ ) and Image $\mathrm{J}^{18}$, software processing packages.

After the end of the $\mathrm{CO}_{2}$ sorption/desorption experiment the coal core was recovered, set in epoxy, and polished. Using the CT images obtained, the orientation of the core was determined, and a petrographic examination of the macerals and minerals in the one of the polished surfaces of the coal core was performed.

\section{RESULTS and DISCUSSION}

\section{CT Sorption}

From the calibration measurements and equation (1) we obtained the following set of three equations for water, silica, and aluminum, respectively: 


$$
\begin{gathered}
1.00 \mathrm{~g} / \mathrm{cm}^{3}=\mathrm{A}[11.5 \mathrm{CTN}]+\mathrm{B}[-95 \mathrm{CTN}]+\mathrm{C} \\
2.20 \mathrm{~g} / \mathrm{cm}^{3}=\mathrm{A}[1755 \mathrm{CTN}]+\mathrm{B}[1162 \mathrm{CTN}]+\mathrm{C} \\
2.699 \mathrm{~g} / \mathrm{cm}^{3}=\mathrm{A}[2725 \mathrm{CTN}]+\mathrm{B}[1780 \mathrm{CTN}]+\mathrm{C}
\end{gathered}
$$

Equations (2) gave the following values of the parameters $\mathrm{A}, \mathrm{B}$, and $\mathrm{C}$ for calculation of (bulk) mass densities from equation (1) and the $\mathrm{CT}$ numbers measured at $80 \mathrm{kV}$ and $130 \mathrm{kV}: \mathrm{A}=2.07$ $\mathrm{g} / \mathrm{CTN} \mathrm{cm}{ }^{3}, \mathrm{~B}=-0.806 \mathrm{~g} / \mathrm{CTN} \mathrm{\textrm {cm } ^ { 3 }}$, and $\mathrm{C}=1206.23 \mathrm{~g} / \mathrm{cm}^{3}$.

Figure 2 illustrates the density variations in each trans-axial cross section of the coal sample. The scans were obtained with the core under vacuum. The light blue color represents the lower density coal matrix, while the colors toward red represent higher density intrusions in the coal. It can be seen that the middle-lower left area of each slice shows a higher density then other regions. The average bulk density of the sample calculated from the CT data was $\rho=1.20 \mathrm{~g} / \mathrm{cm}^{3}$, which was within $1.5 \%$ of the density $\left(\rho=1.22 \mathrm{~g} / \mathrm{cm}^{3}\right)$ calculated from the mass and volume measurements.

Figure 3a illustrates the spatial distribution of sorbed $\mathrm{CO}_{2}$ after 165 hours of injection at 195 psig. It can be seen that slices further away from the injection port contained less $\mathrm{CO}_{2}$. Also, one can observe that the slices did not sorb $\mathrm{CO}_{2}$ uniformly, and that the lower-left portion of the each slice sorbed very little $\mathrm{CO}_{2}$.

Figure $3 \mathrm{~b}$ is a plot of the average $\mathrm{CO}_{2}$ concentrations in various slices vs. time of injection at 195 psig, up to 165 hours of injection. (Slice 1 is at the injection port; slice 2 was contiguous to it; and each slice was $2 \mathrm{~mm}$ thick.) It is clear that the diffusion-sorption process had not reached equilibrium over a $2 \mathrm{~cm}$ distance even after 165 hours.

Figures $4 \mathrm{a}, 4 \mathrm{~b}$, and $4 \mathrm{c}$ show $\mathrm{CO}_{2}$ sorption images for each of the slices at injection pressures 325 psig, $450 \mathrm{psig}$, and $600 \mathrm{psig}$, respectively. Careful visual observation of the images confirms that slices close to the injection point had sorbed more $\mathrm{CO}_{2}$ than slices not as close to it, even after the end of the fourth pressure step after a total $\mathrm{CO}_{2}$ exposure time (for all injection pressures) of 1065 hours (6 weeks).

The average sorption for each of the (contiguous) slices near the end of the injection period for each $\mathrm{CO}_{2}$ pressure is plotted in Figure 5. The sorption seems to decrease almost monotonically from the $\mathrm{CO}_{2}$ inlet toward the opposite end of the core.

Figure 6 is a plot of the "apparent sorption isotherms" for various slices as obtained from the CT data. For slice 1, with the shortest diffusion length, the $\mathrm{CO}_{2}$ sorption at the end of step 3 (400 psig, 839 hours total injection time) and that at the end of step 4 (600 psig, 1005 hours) are very nearly the same, indicating that for this slice sorption equilibrium may have been achieved. Sorption equilibrium in the other slices was not obtained, as indicated by the monotonic decrease of $\mathrm{CO}_{2}$ concentration with distance from the injection inlet.

From Figures 3-6 one can see that the sorption of $\mathrm{CO}_{2}$ was non-uniform in each slice, and also along the length of the core. It also was observed that the sorption seemed to be more pronounced in the upper right regions of the slices and less in the lower left regions. 
Consequently, two rhomboidal "regions of interest" (ROI's) of approximately the same size were defined, one in each of these regions. Figure $7 \mathrm{a}$ illustrates the locations of these regions. The density before sorption was calculated for each of these two regions in each slice of the sample. In Figure $7 \mathrm{~b}$ these densities, along with the average density for the entire slice, are plotted vs. length along the core from the injection end. As expected, the coal densities in the ROI's are different from the average slice density. In region 1 the density is higher then the average density of the core; however, its trend along the length of the core tends to follow that of the average density. The density in region 2 is always lower than the density in region 1; however, the variations are much larger, and the density is sometimes larger, sometimes smaller, than the curve for the average core density.

Figure 7c is a plot of sorption vs. length along the core for region 1, region 2, and the entire slice, each measured after 1065 total hours of injection. These curves illustrate the inhomogeneity of the sorption in the core. The region 1 sorption curve is much lower then the average sorption, confirming the visual observations from the pictures, while the region 2 sorption is much higher than that of region 1, and generally higher then the average sorption. It can be also observed that, in general, the higher the coal density, the lower the sorption. (See, also, Figure 11.) For the region 1 the calculated sorption seems to dip to negative values (slices 4 and 11). It is unclear whether the negative values are erroneous, or due to changes in density in these regions, from swelling or other effects.

In the last part of the experiment, we gradually desorbed the $\mathrm{CO}_{2}$ in three steps: a) the $600 \mathrm{CO}_{2}$ inlet pressure was reduced to $400 \mathrm{psig}$, with a corresponding decrease of confining pressure (from 800 psig to $600 \mathrm{psig}$ ); b) the $\mathrm{CO}_{2}$ inlet pressure was reduced from 400 psig to 200 psig (confining pressure $400 \mathrm{psig}$ ); and c) the inlet pressure was reduced to atmospheric pressure (200 psig confining pressure). As shown above, during the injection phase the $\mathrm{CO}_{2}$ concentration exhibited the expected decrease from inlet to far end of the core. And, as plotted in Figure 8, near the end of the last stage of the desorption the concentration exhibited the expected decrease from far end of the core to the outlet. The behavior indicated by the upper two curves in Figure 8 is not so intuitive, and their interpretation has not yet been completed.

\section{Density histograms}

Figures 2-7 illustrate the heterogeneities in the coal sample and its sorption properties. In principle, the CT instrument may be able to detect heterogeneities on a scale as small as that of individual voxels. There were circa 9900 voxels in each slice, each voxel representing a parallelepiped of (measured) dimensions $0.21 \mathrm{~mm} \times 0.21 \mathrm{~mm} \times 2.0 \mathrm{~mm}$.

Figure 9 represents the histogram for the density of slice 1 of the evacuated core (before gas injection). The average density for the slice is $1197.9 \mathrm{mg} / \mathrm{cm}^{3}$. The average skewness factor (measure of the asymmetry) of the distribution is +0.67 . (For a perfectly symmetrical distribution the skewness factor is 0 .)

The density distribution in Figure 10 represents the voxel densities in slice 1 after 1065 total hours of exposure to $\mathrm{CO}_{2}$, at the end of 600 psig sorption cycle. It shows that the average voxel density increased to $1231 \mathrm{mg} / \mathrm{cm}^{3}$, and skewness to 0.88 . Figure 11 illustrates the relationship between the density difference caused by sorption (density after sorption minus initial density) and initial coal density. The results suggest that lower density macerals sorbed more $\mathrm{CO}_{2}$ than 
did higher density macerals. This conclusion is consistent with a comparison of the density and concentration plots in Figures $7 \mathrm{~b}$ and 7c for regions 1 and 2.

Figure 12 shows the density distribution in slice 1 at elapsed time $t=1667$ hours ( 10 weeks), after the core had desorbed $\mathrm{CO}_{2}$ (in three stages) for 602 hours. The average density in the slice was $1198.9 \mathrm{mg} / \mathrm{cm}^{3}$, vs. $1197.9 \mathrm{mg} / \mathrm{cm}^{3}$ initially. This very small difference $(0.08 \%)$ seems to indicate that, at most, a very small amount of $\mathrm{CO}_{2}$ remained in the core. However, while the average density of the slice after degasification returned to almost its pre-injection value, the frequency distribution of the voxel densities in the slice did not. (The calculated average skewness of the distribution was 0.82 after degasification, 0.67 before injection of $\mathrm{CO}_{2}$; comparison of Figures 9 and 12 reveals obvious changes in the frequency distribution.) The latter change suggests a structural re-arrangement in the slice may have occurred due to $\mathrm{CO}_{2}$ sorption and/or the confining pressure.

\section{Petrographic observations}

As it was mentioned earlier, the lower left "corner" (see rhomboid) of the core did not sorb $\mathrm{CO}_{2}$ as well as most of the other regions of the core. The density calculations prior to $\mathrm{CO}_{2}$ injection showed relatively higher density constituents in broken bands in the core. Some of these bands were in the low sorption region. These bands were interpreted prior to petrographic examination to indicate the direction of the bedding planes in this sample. In actuality these bands are composed of higher density inertinite macerals (fusinite, semifusinite, inertodetrinite) that were often associated with clay filling of cell lumens and do indeed indicate bedding plane direction. These bands are fairly consistent and appear in other areas of the core.

Specifically, in the low sorption region, it was noted under petrographic examination that this area was composed mainly of trimaceral material (vitrinite, liptinite, inertinite), as shown in Figure 13. One observation of this region of the core was that the macerals were tightly intermixed and that liptinite (sporinite) and inertinite (fusinite, inertodetrinite) dominated the region as consistent bands. Moving further along into the interior of the core it was noticed, as seen in Figure 14, that there were consistent bands of vitrinite that alternated with mixed bands of intertinite and liptinite. These mixed bands were different than the trimaceral bands in the low sorption region in that there was not a high degree of tight intermixture as seen in the low sorption region.

\section{Isotherm Comparison: Confined Coal vs. Powder}

Figure 15 compares the sorption in slice 1 of the confined coal core as measured by $\mathrm{CT}$ at $21{ }^{\circ} \mathrm{C}$ with the sorption obtained from the manometric experiment with the unconfined powder at 30 ${ }^{\circ} \mathrm{C}$. Because the sorption should be slightly smaller at the higher temperature, the difference between the two isotherms is actually somewhat larger than the Figure implies. It is impossible from these exploratory experiments to separate the effects of experimental method (CT vs. manometry), sample size (powder vs. core), confining pressure (none vs. several hundred psig), and degree of attainment of equilibrium on the difference between the two isotherms. However, it remains clear that many more measurements on confined and unconfined cores are needed for the attainment of physical property data needed for enhanced coal bed methane/sequestration projects. 


\section{CONCLUSIONS}

Noninvasive, dual energy X-ray computed tomography provides an accurate way to calculate density variations and $\mathrm{CO}_{2}$ concentrations, sorptions, and transport rates in coal cores at reservoir confining pressures. Average slice density increased during the $\mathrm{CO}_{2}$ intake periods. Also, the slice-average $\mathrm{CO}_{2}$ concentrations increased with time and with increasing $\mathrm{CO}_{2}$ injection pressure. The $\mathrm{CO}_{2}$ concentrations were higher for slices close to the injection point, and less as the distance from intake increased. This indicates that diffusion kinetics can play a very important role in a sequestration process, even for small cleat spacing. Desorption experiments further illustrated the importance of sorption kinetics for the sequestration process.

When small regions of interest inside the core were chosen for analysis, very high density variations were observed compared to the sample average. The calculated $\mathrm{CO}_{2}$ sorption for a region with higher density showed markedly lower sorption values than the slice averages, while the region with lower density showed a higher sorption capacity. This finding was also confirmed by analysis of data for individual voxels $(0.21 \mathrm{~mm} \times 0.21 \mathrm{~mm} \times 2.0 \mathrm{~mm})$. Changes in the density histograms from before $\mathrm{CO}_{2}$ injection to after virtually complete desorption suggest an internal structural rearrangement in the coal core.

Petrographic work implied that the regions of lower sorption were the higher- density inertinite macerals (fusinite, semifusinite, inertodetrinite), which were often associated with clay filling of cell lumens.

$\mathrm{CO}_{2}$ sorption seems to be reduced by application of a confining pressure. However, further studies need to be performed, especially on confined coals, to address differences in experimental methods, and possible changes in coal structure due to confinement.

\section{AKNOWLEDGEMENTS}

This work was funded entirely by the Office of Fossil Energy, U.S. Department of Energy. We thank Bryan Tennant for performing the scans and other experimental help.

\section{REFERENCES}

1. Puri, R. and D. Yee. “Enhanced Coalbed Methane Recovery,” SPE paper 20732. Proceedings of the $65^{\text {th }}$ Annual Technical Conference and Exhibition of the Society of Petroleum Engineers. pp. 193-202. New Orleans, LA, September 23-26, 1990.

2. Pagnier, H.J.M., F. vanBergen, L. van deVate, L. Hills, and W. Bamber. "Inventory of the potential of combined coalbed methane production carbon dioxide disposal in the Dutch subsurface" in Proceedings of XIV International Congress on the Carboniferous and Permian (ICCP) 109, 1999.

3.Mavor, M.J., Owen, L.B., Pratt, T.J.: "Measurement and evaluation of Coal Sorption Isotherms", Paper SPE 20728, presented at the $65^{\text {th }}$ Annual Technical Conference and Exhibition, New Orleans, September 23-26, 1990. 
4. Bromhal, G.; Sams, W. N.; Jikich, S.A.; Smith, D. H., (2005). "Simulation of CO2 Sequestration in Coal Beds: The Effects of Sorption Isotherms," Chem. Geol. 217, 201-11.

5. Goodman, A.L.; Busch, A.; Duffy, G.J.; Fitzgerald, J.E.; Gasem, K.A.M.; Gensterblum, Y.; Kroos, B.M.; Levy, J.; Ozdemir, E.; Pan, Z.; Robinson Jr., R.L.; Schroeder, K.; Sudibandriyo, M.; White, C.M., (2004). "An Inter-Laboratory Comparison of CO2 Isotherms Measured on Argonne Premium Coal Samples," Energy and Fuels, 18, 1175-1182.

6.Bustin, R.M., Clarkson, C.R.: "Binary gas adsorption/desorption isotherms: effect of moisture and coal composition upon carbon dioxide selectivity over methane", International Journal of Coal Geology, 42, (2000), 241-271.

7. Smith, D. H.; Sams, W. N.; Bromhal, G.; Jikich, S.; Ertekin, T., (2005). "Simulating Carbon Dioxide Sequestration/ECBM Production in Coal Seams: Effects of Permeability Anisotropies and the Diffusion-Time Constant, SPE 84423-PA," SPE Reservoir Evaluation \& Engineering, 8, 156-163.

8. Jikich, S. A., Bromhal, G.; Gorucu, F. B; Sams, W. N.; Ertekin, T.; Smith, D. H., (2004). "Economics for Enhanced Coalbed Methane and Sequestration of CO2 with Horizontal Wells," 2004 Proc., SPE Eastern Regional Meeting, Charleston, West Virginia, September 15-17.

9. Gorucu, F. B.; Jikich, S. A.; Bromhal, G. S.; Sams, W. N.; Ertekin, T.; Smith, D. H., (2007). "Matrix Shrinkage and Swelling Effects on Economics of Enhanced Coal Bed Methane Production and CO2 Sequestration in Coal," SPE 97963, SPE Reservoir Evaluation \& Engineering, Vol 10, August 2007.

10. Karacan, C. O., Okandan, E:"Adsorption and gas transport in coal microstructure: investigation and evaluation by quantitative X-Ray CT imaging”, Fuel, 80, 509-520.

11. Karacan, C. O.; Mitchell, G. D.: "Behavior and effect of different coal microlithotypes during gas transport for carbon dioxide sequestration into coal seems", Int. J. Coal Geol. 2003, $53,201-217$.

12. Karacan, C. O.: "Heterogeneous Sorption and Swelling in a Confined and Stressed Coal during CO2 Injection”, Energy Fuels 2003, 17, 1595-1608.

13. Smith, D.H, Jikich, S.A., Seshadri, K.: "Carbon Dioxide Sorption Isotherms and Matrix Transport Rates for Non-Powdered Coal, paper 0721, Proceedings, International Coalbed Methane Symposium, Tuscaloosa, AL, May 21-25, 2007.

14.Duliu, O.G.: "Computer axial tomography in geosciences: and overview”, Earth Science Reviews, vol.48, 1999, p.265-281.

15. Siddiqui, S., Khamees, A.A.: "Dual -Energy Scanning Applications in Rock Characterization", paper SPE 90520, presented at the SPE Annual Conference and Exhibition, Houston, TX, 26-29 September, 2004. 
16. Wellington, S.L., Vinegar, H.J.: “X-Ray Computerized Tomography," Journal of Petroleum Technology, August, 1987, p.885.

17. Kehl, B.: VoxelCalc NDT Software User's Guide, KehlCo, Inc., Houston, TX, 2005.

18. Image J: www: rsb.info.nih.gov/ij 


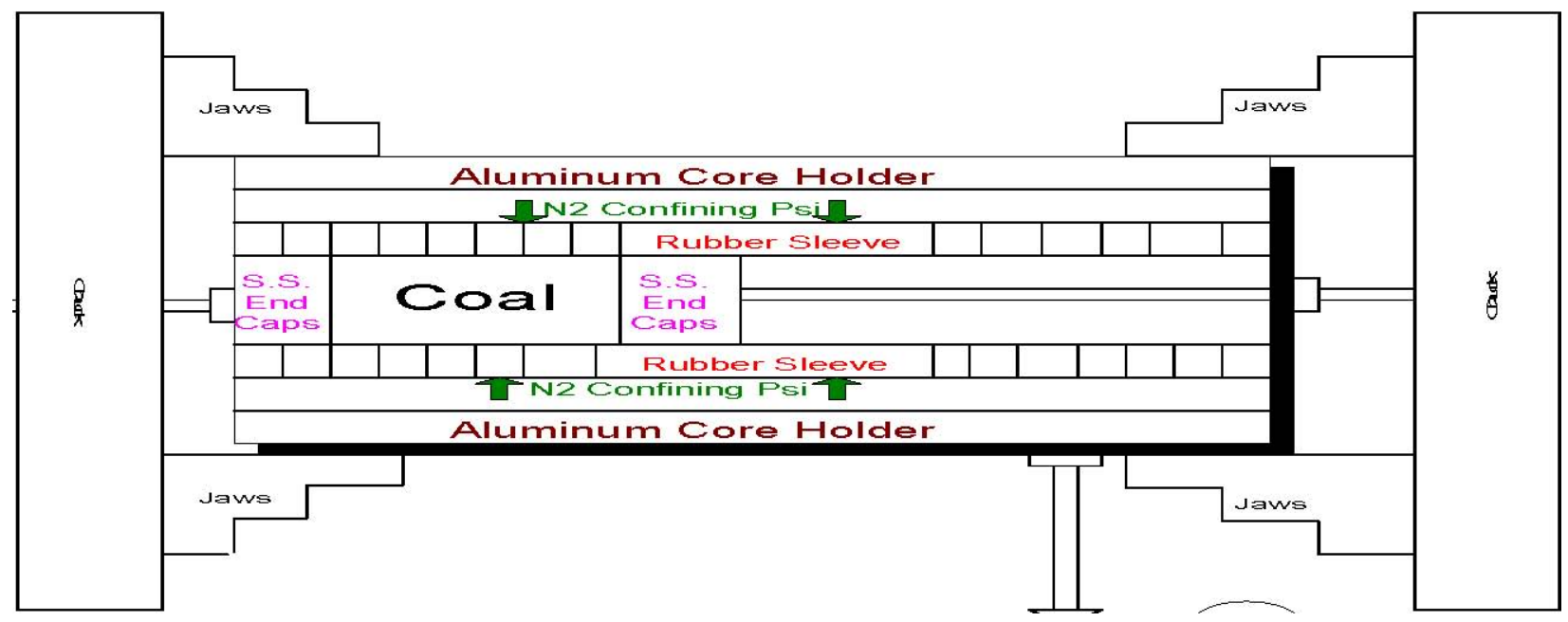

Figure 1. Experimental set-up.
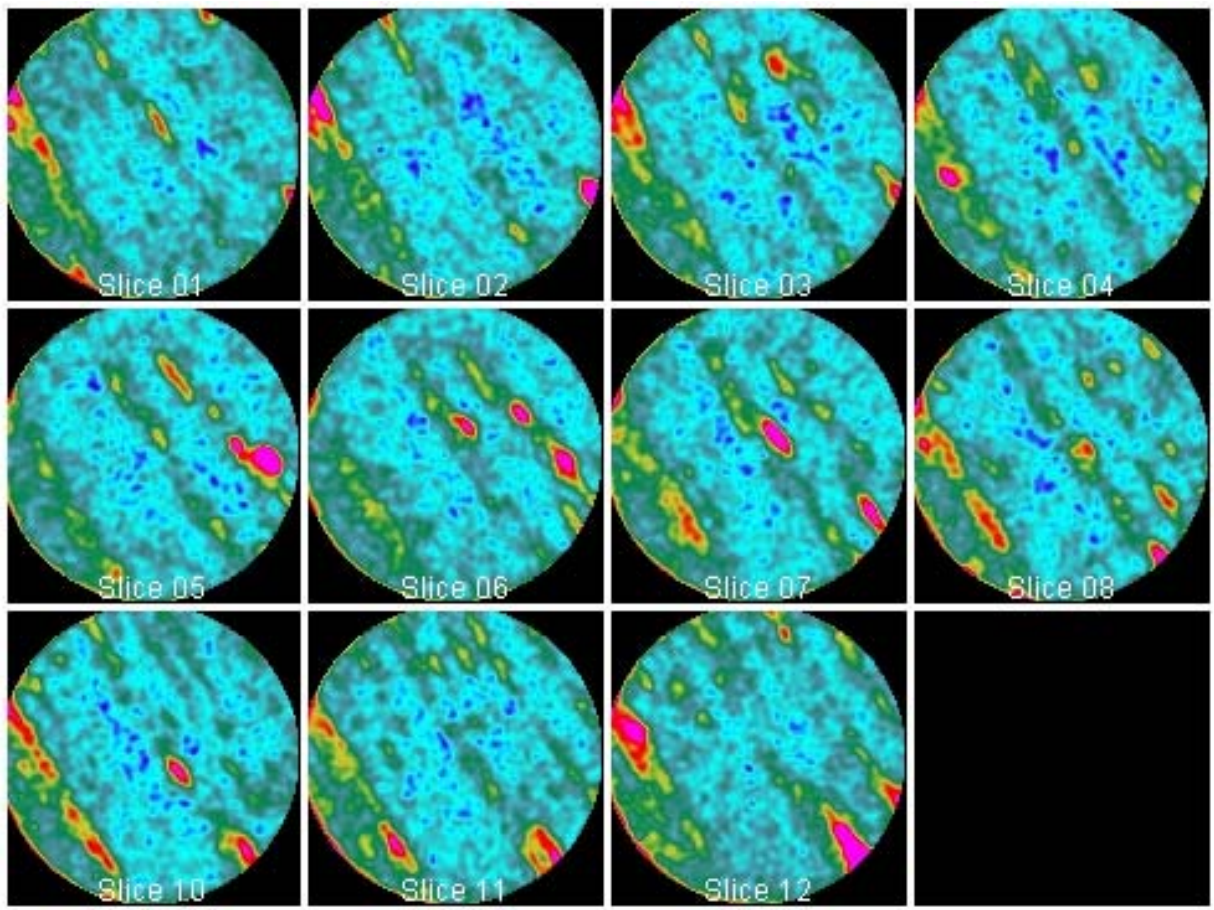

Figure 2. Density variations in the scanned core. 

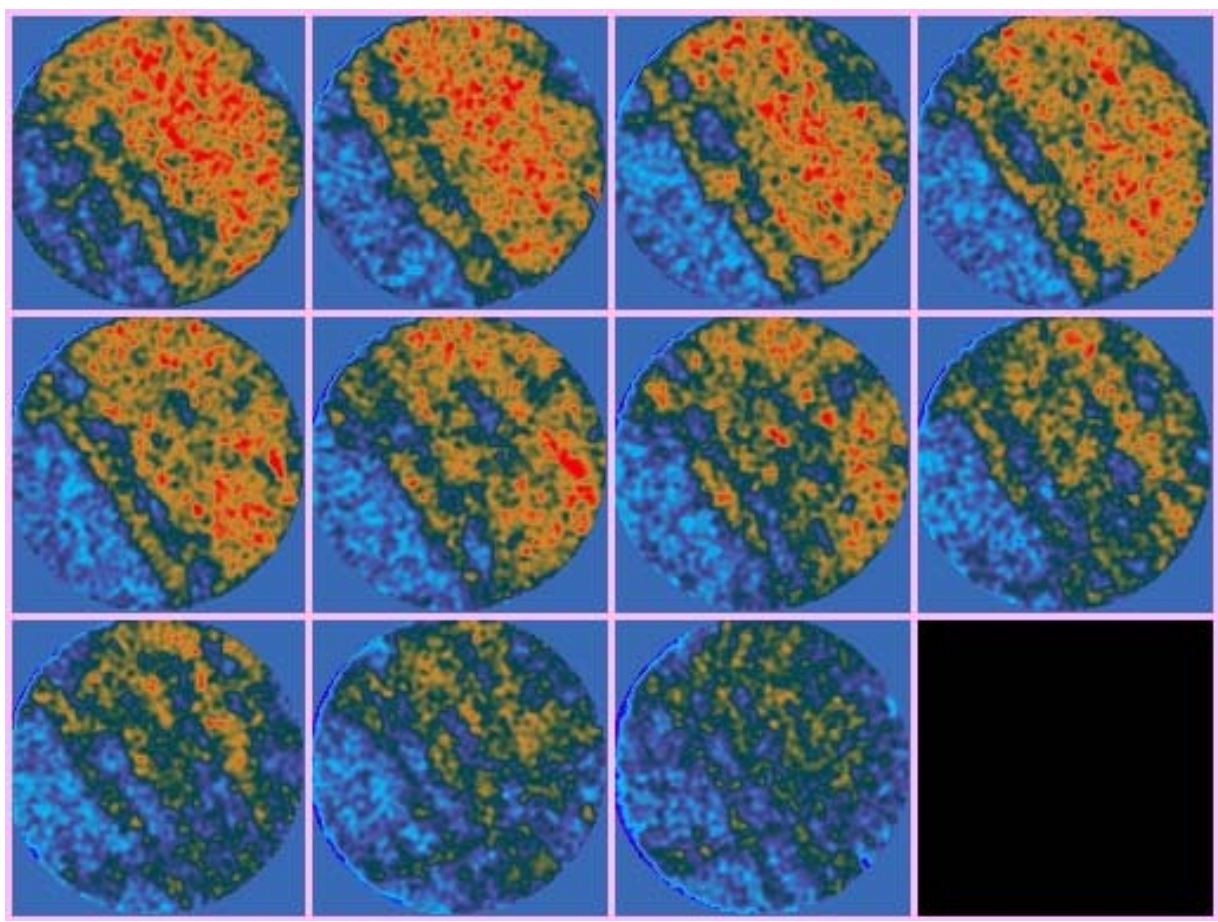

Figure 3a. Changes of sample density caused by $\mathrm{CO} 2$ injection at the end of the first injection pressure step (195 psig).

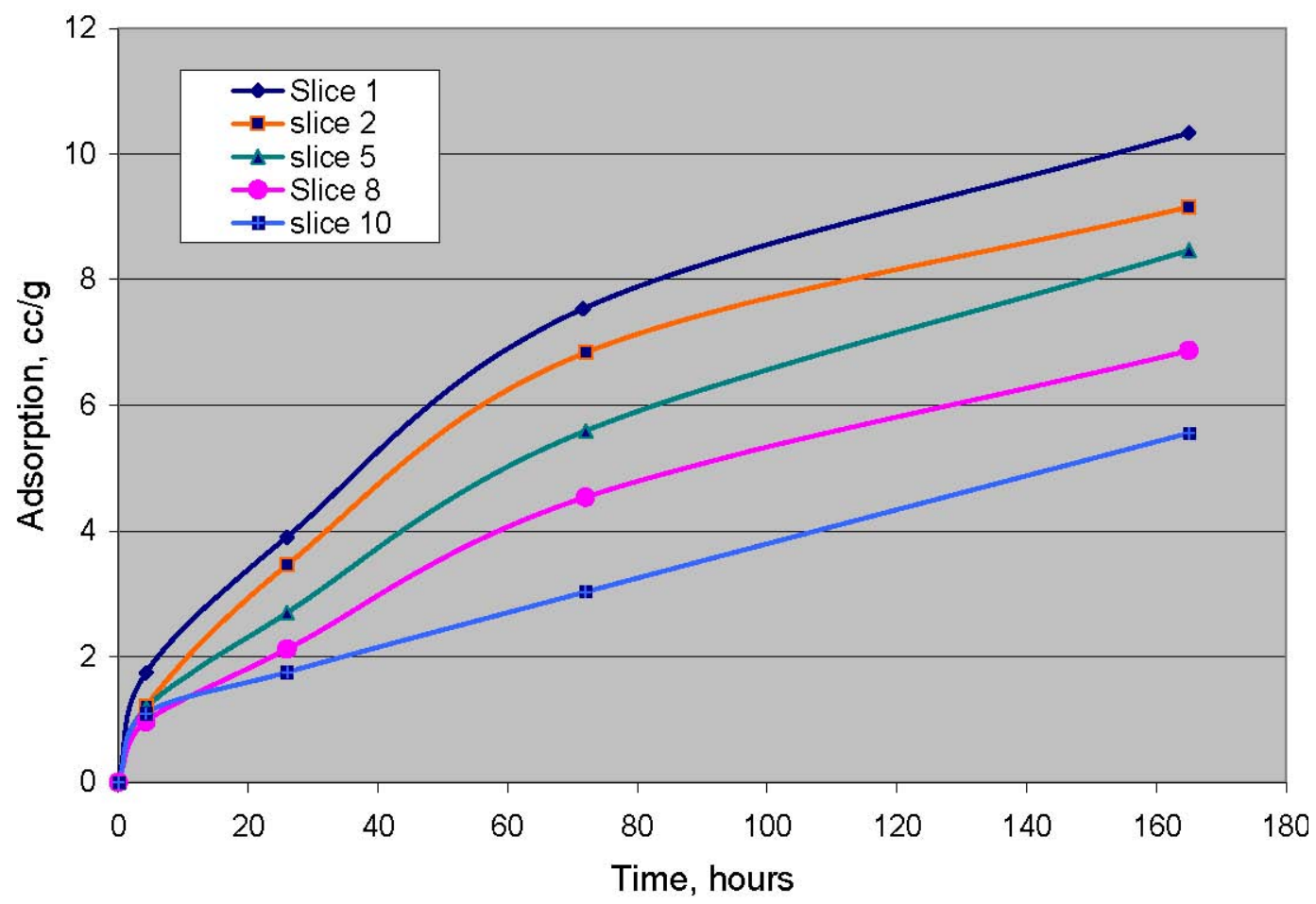

Figure $3 \mathrm{~b}$. CO2 concentrations in various slices vs. time of injection at 195 psig. 

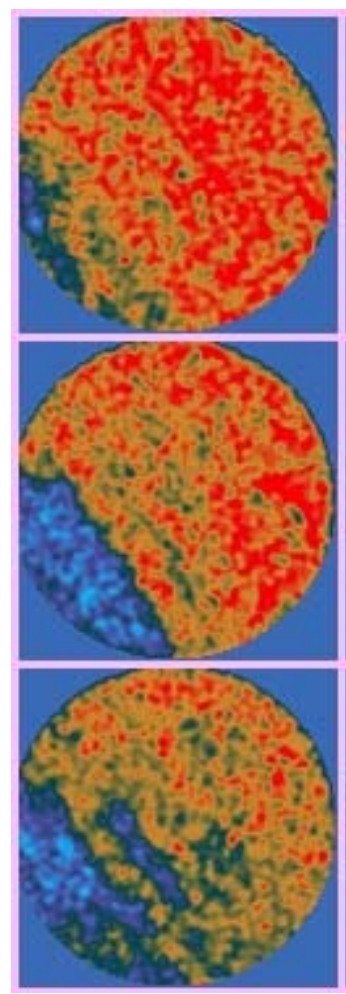

Figure 4a. Changes of sample density caused by $\mathrm{CO} 2$ injection at the end of the second injection pressure step (325 psig).
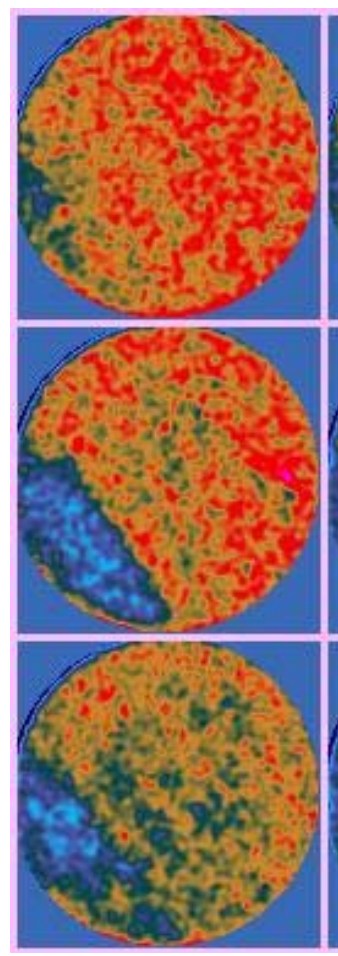

Figure $4 \mathrm{~b}$. Changes of sample density caused by $\mathrm{CO} 2$ injection at the end of the third injection pressure step (450 psig). 


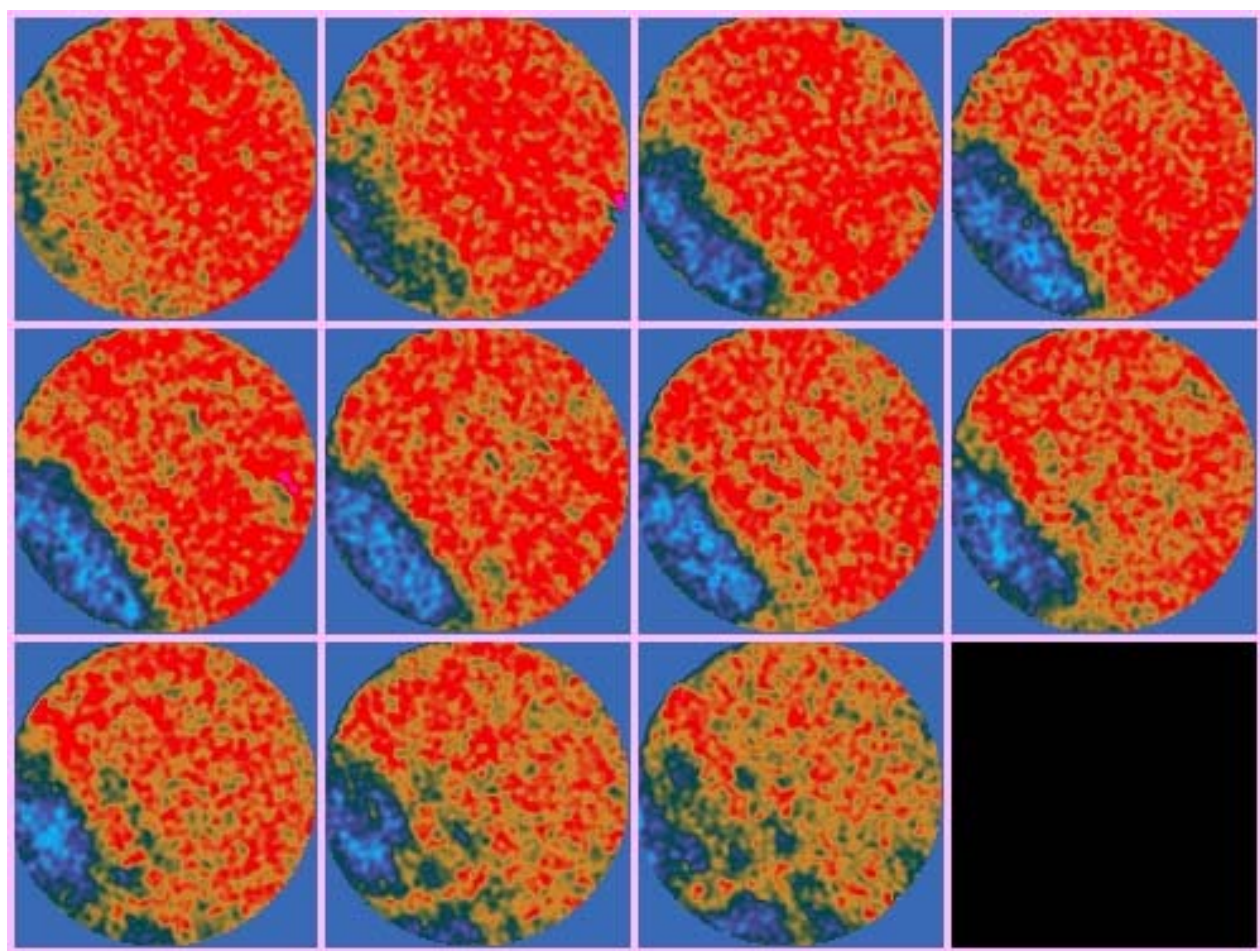

Figure 4c. Changes of sample density caused by $\mathrm{CO} 2$ injection at the end of the fourth injection pressure step (600 psig).

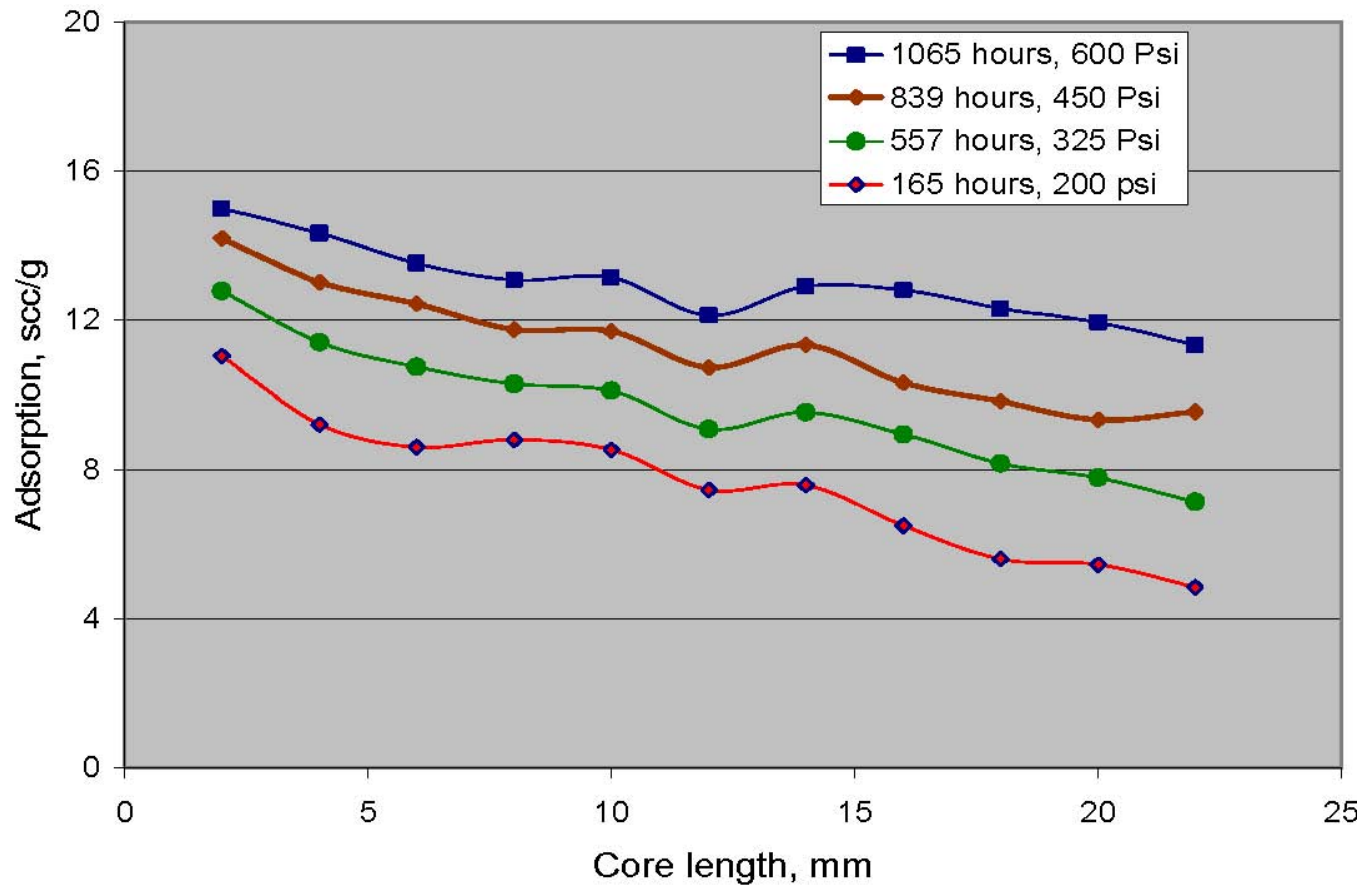

Figure 5. $\mathrm{CO} 2$ concentrations vs. diffusion distance. 


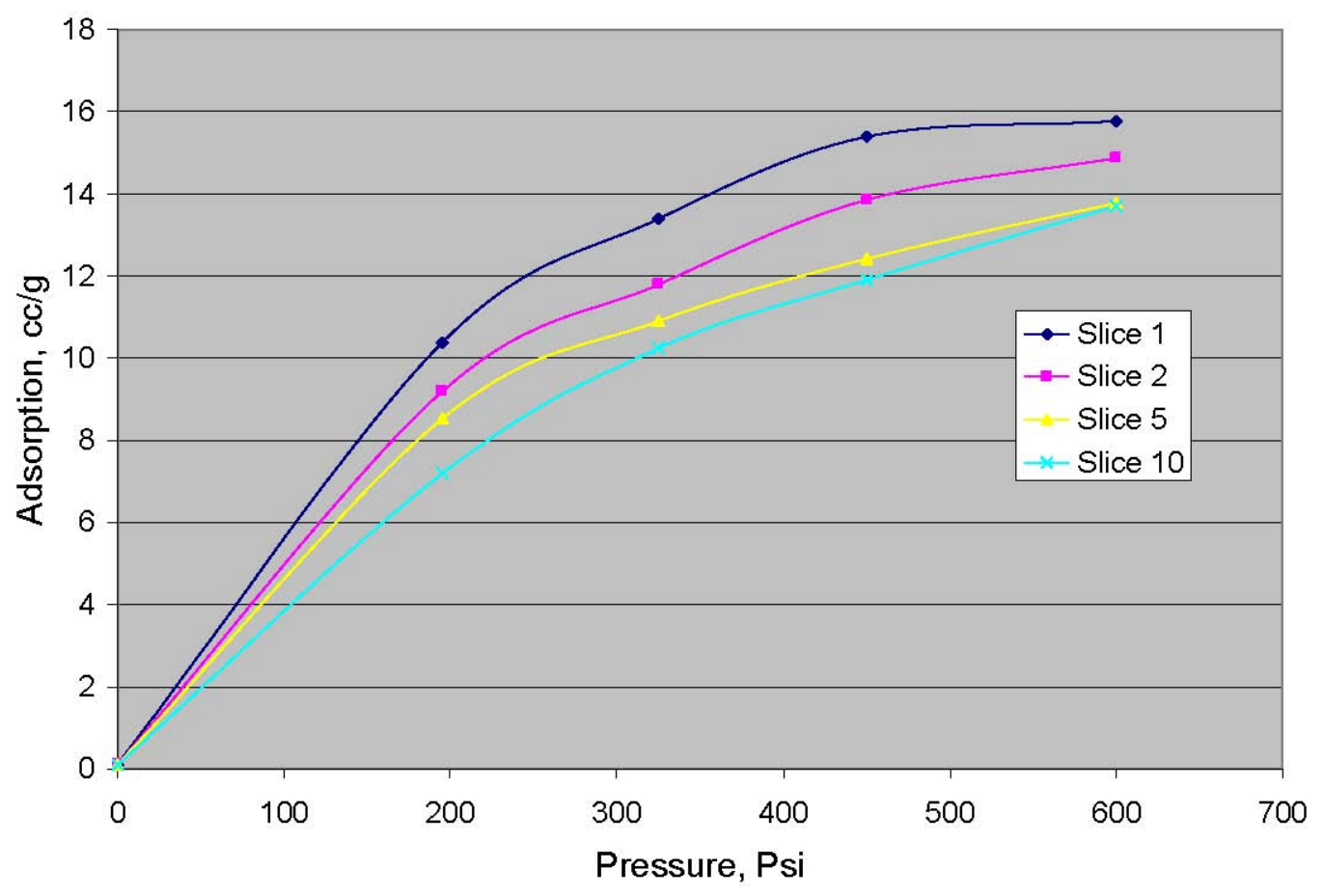

Figure 6. Apparent sorption isotherms for various slices.
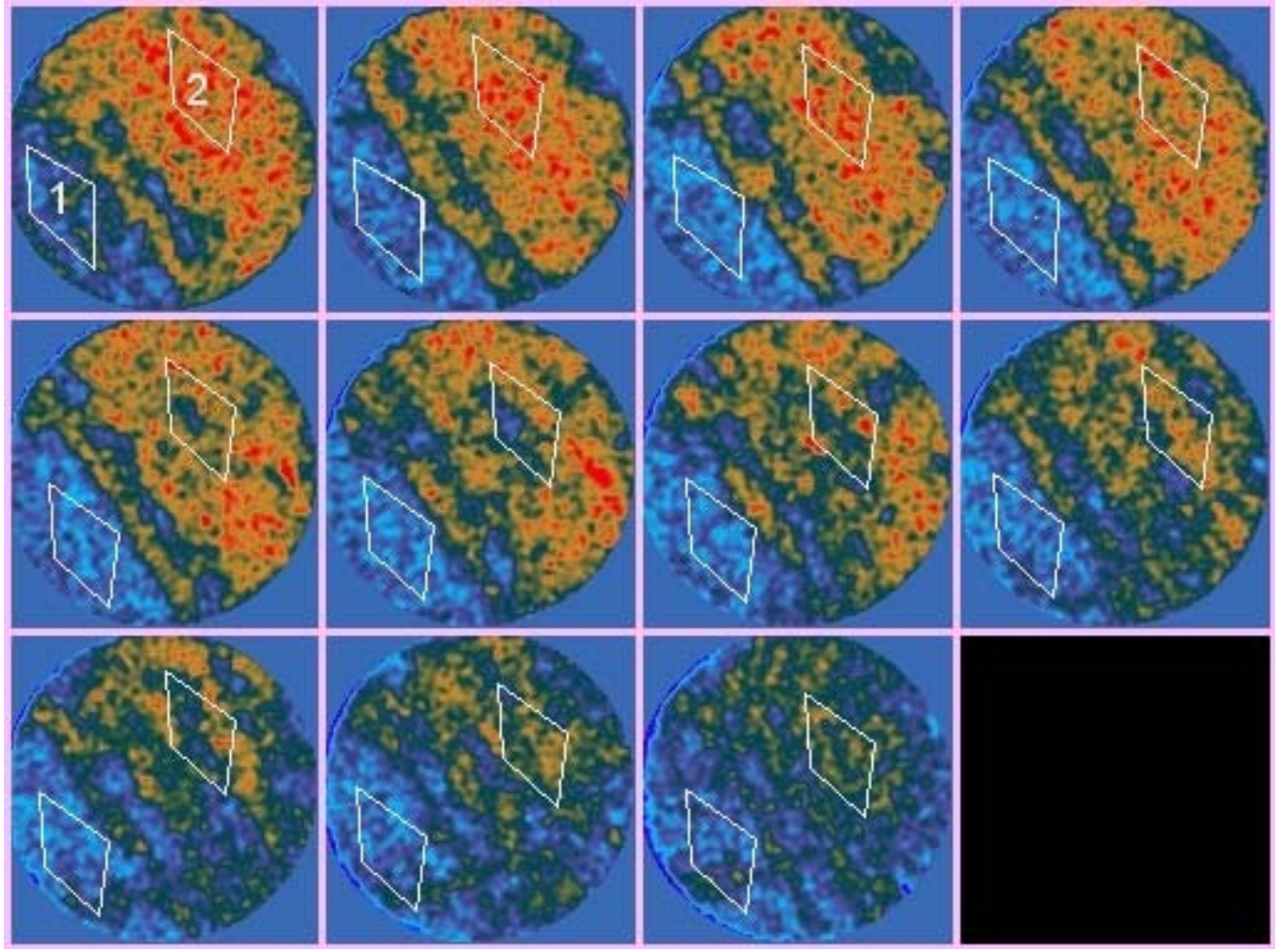

Figure 7a. Locations of rhomboid regions of interest (ROI) 1 and 2. 


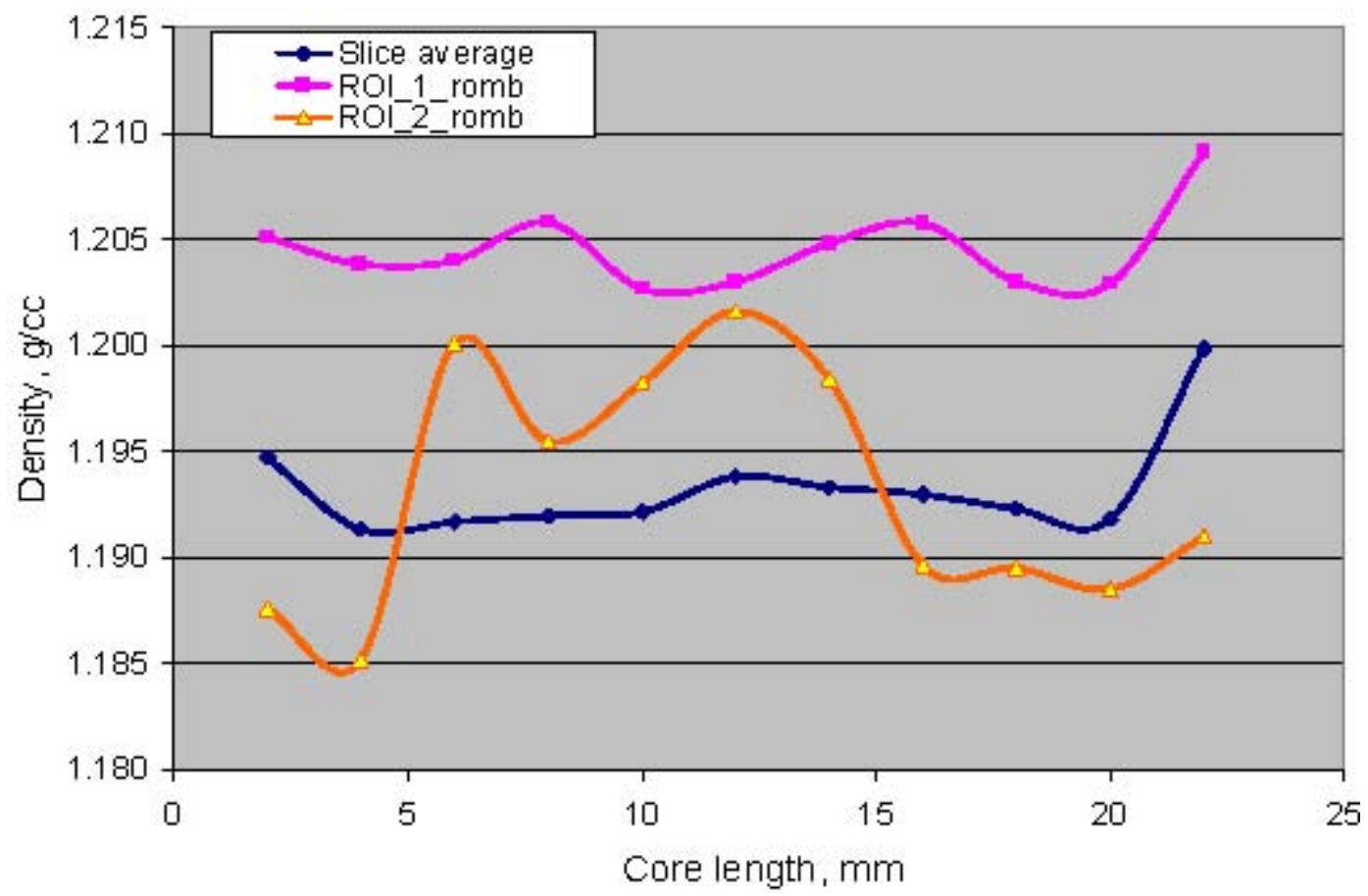

Figure $7 \mathrm{~b}$. Density vs. core length for the complete slices and for the two regions of interest.

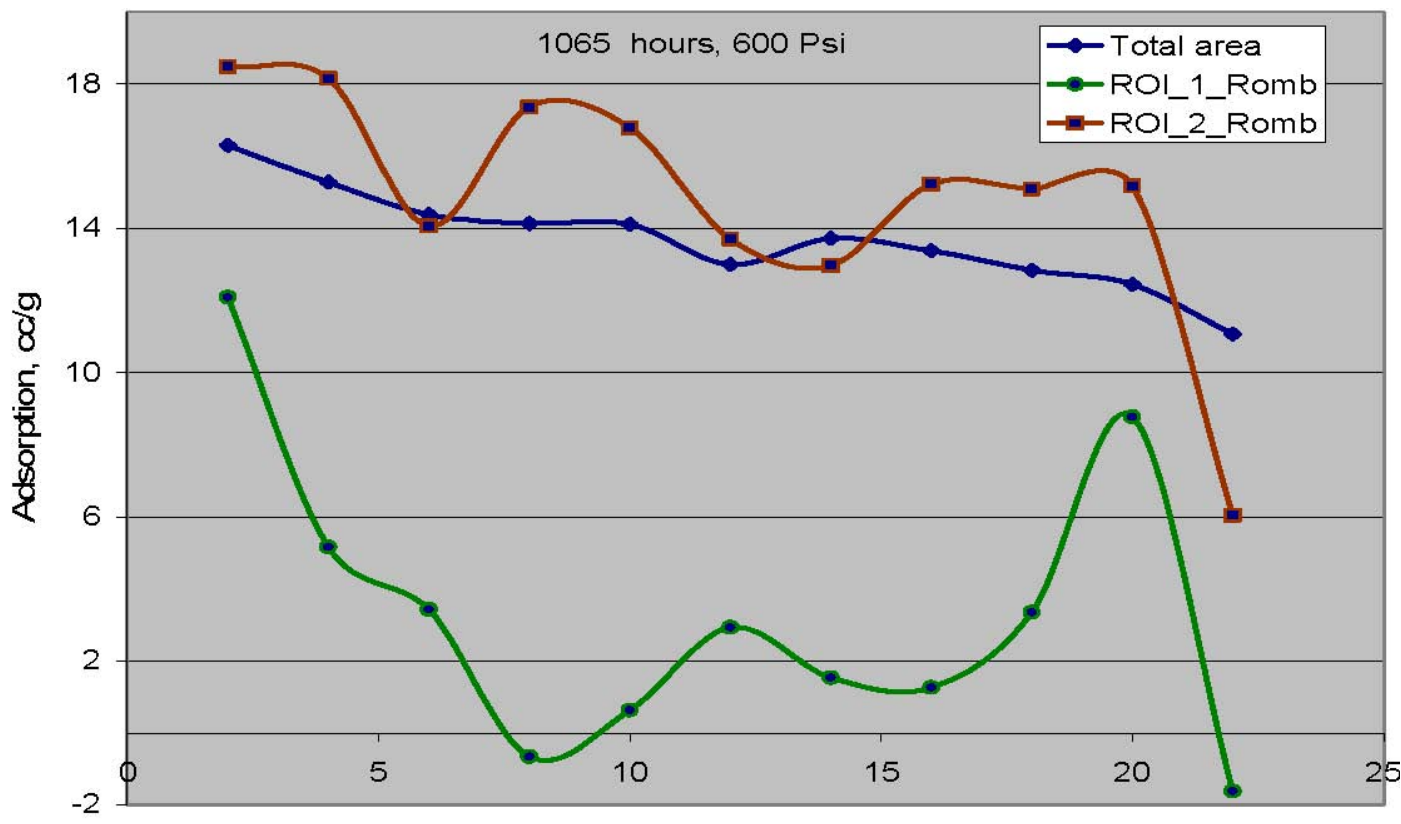

Distance from $\mathrm{CO}_{2}$ injection source, $\mathrm{mm}$

Figure $7 \mathrm{c} . \mathrm{CO} 2$ concentrations vs. core length for the average slice and for the two regions of interest. 


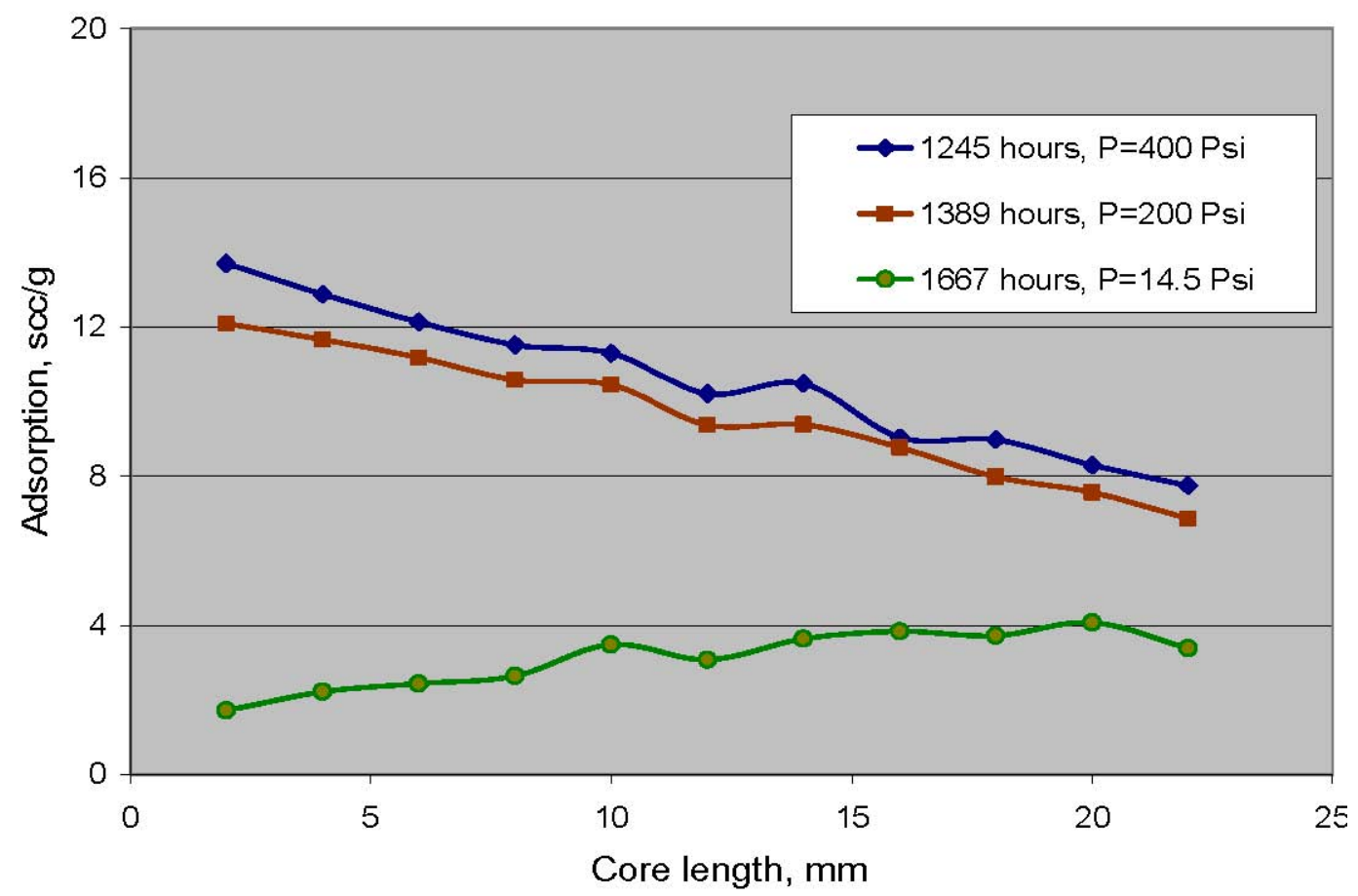

Figure 8. $\mathrm{CO} 2$ concentrations during the desorption experiment vs. distance from the gas outlet.

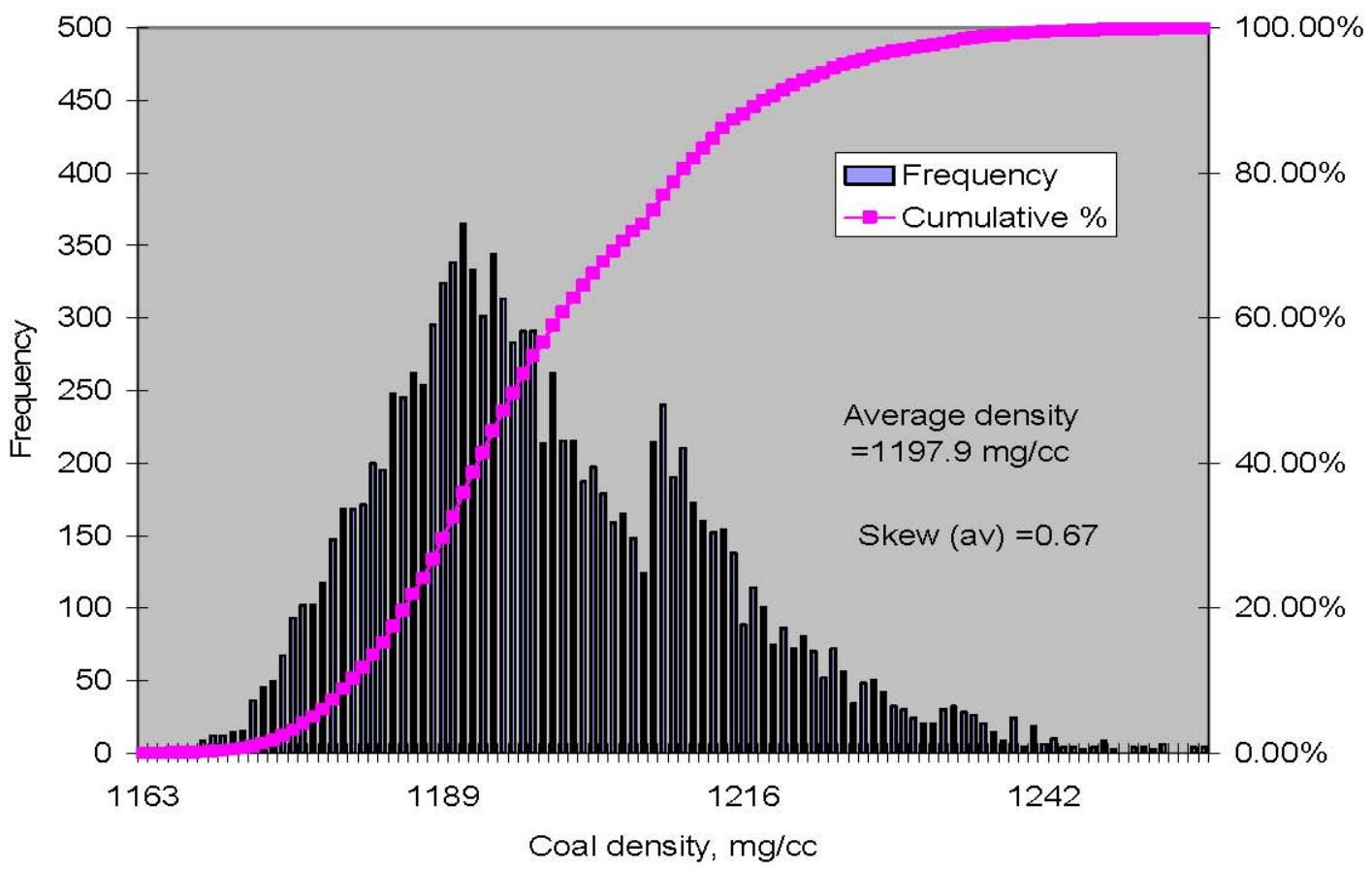

Figure 9. Histogram for the voxel densities of slice 1 of the coal sample before injection of $\mathrm{CO}_{2}$. 


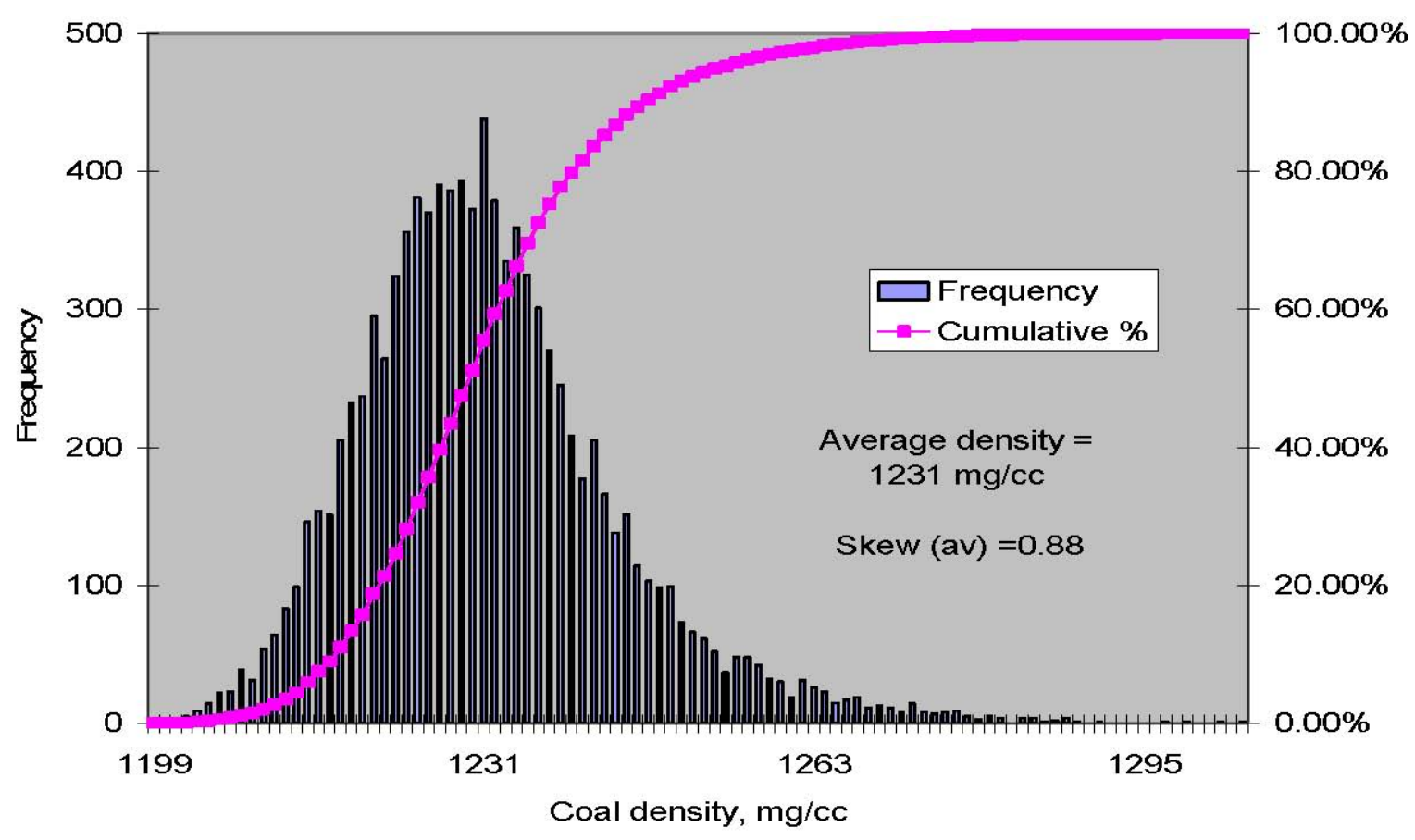

Figure 10. Histogram for the voxel densities of slice 1 after $\mathrm{CO}_{2}$ sorption at $600 \mathrm{psig}$ (total elapsed sorption time 1065 hours).

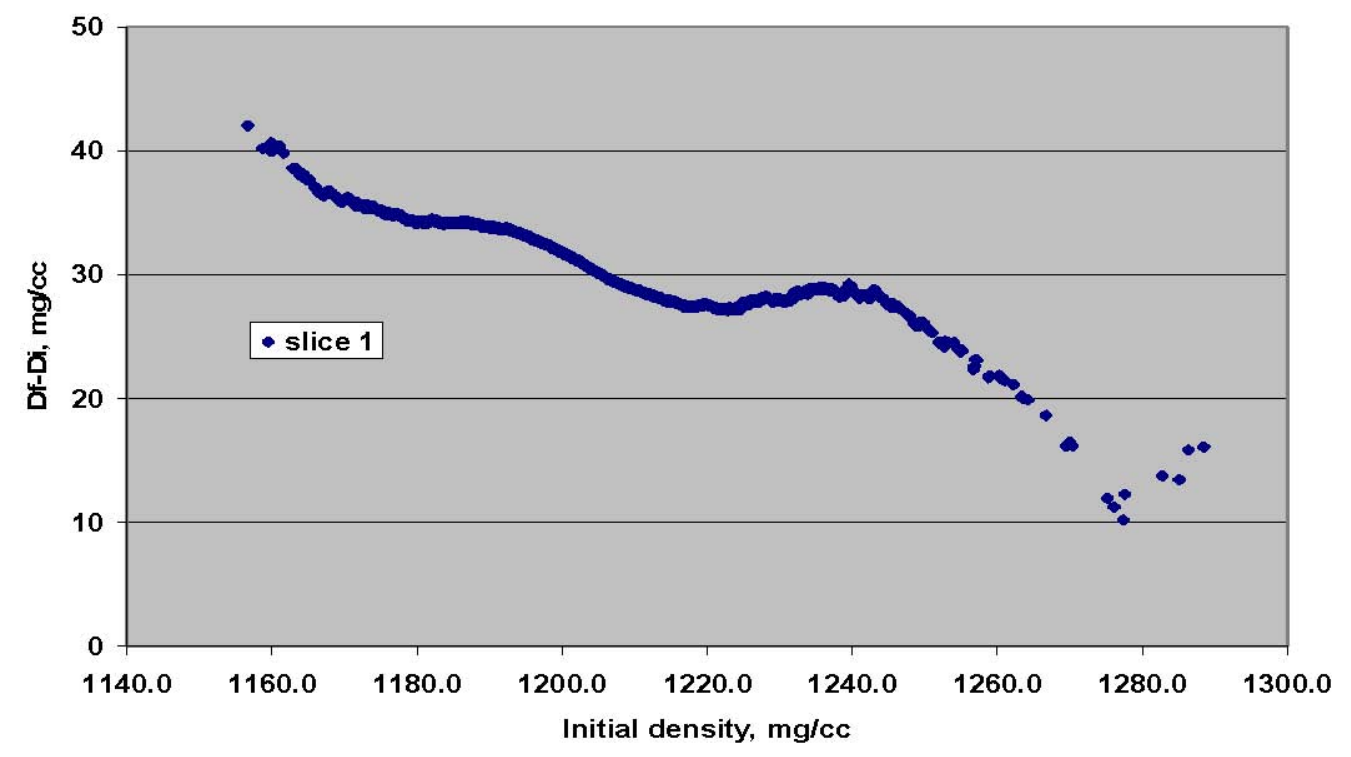

Figure 11. Increase of voxel density due to injection vs. voxel density before injection. 


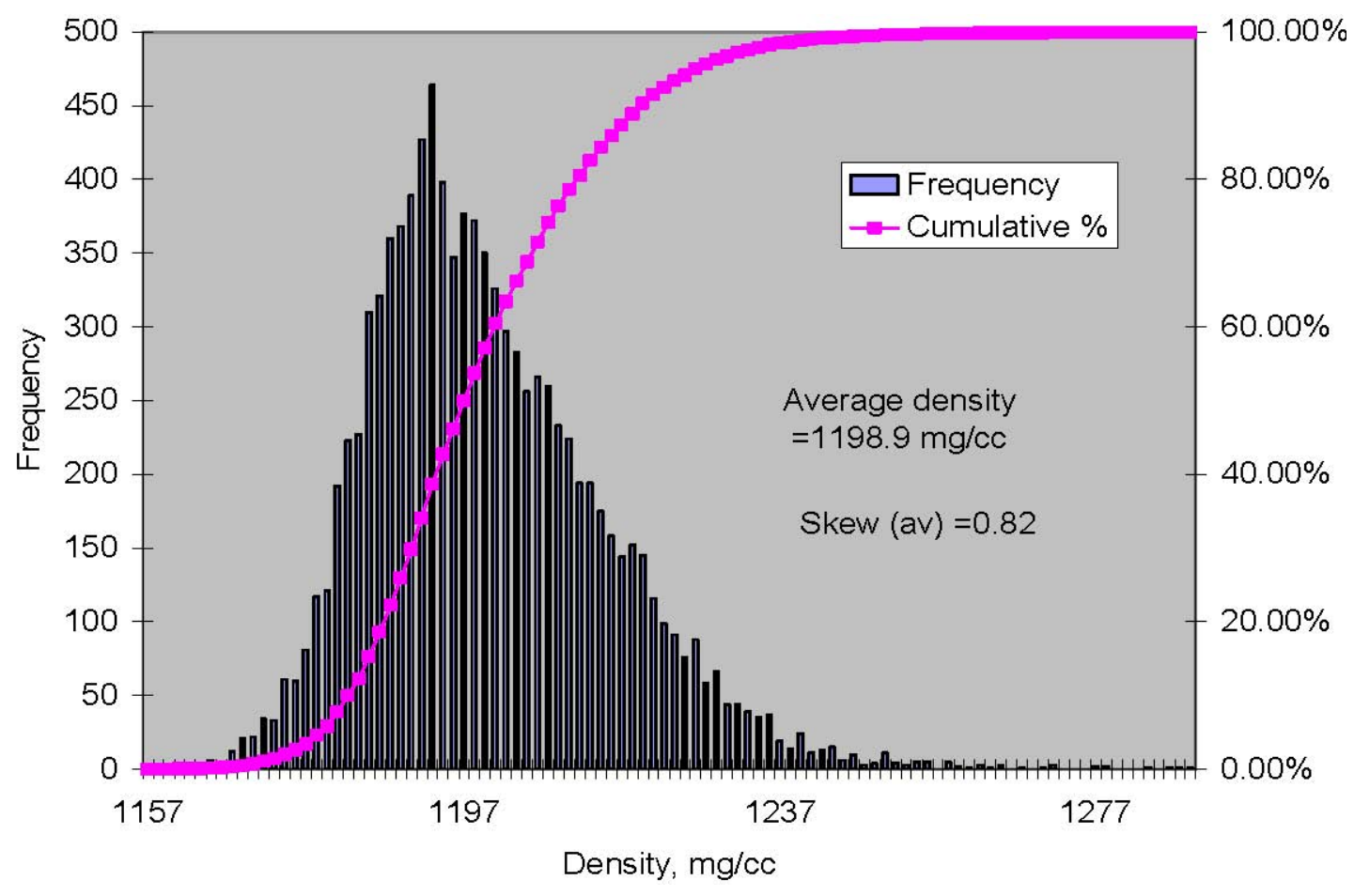

Figure 12. Histogram for the voxel densities after the core was degassed.

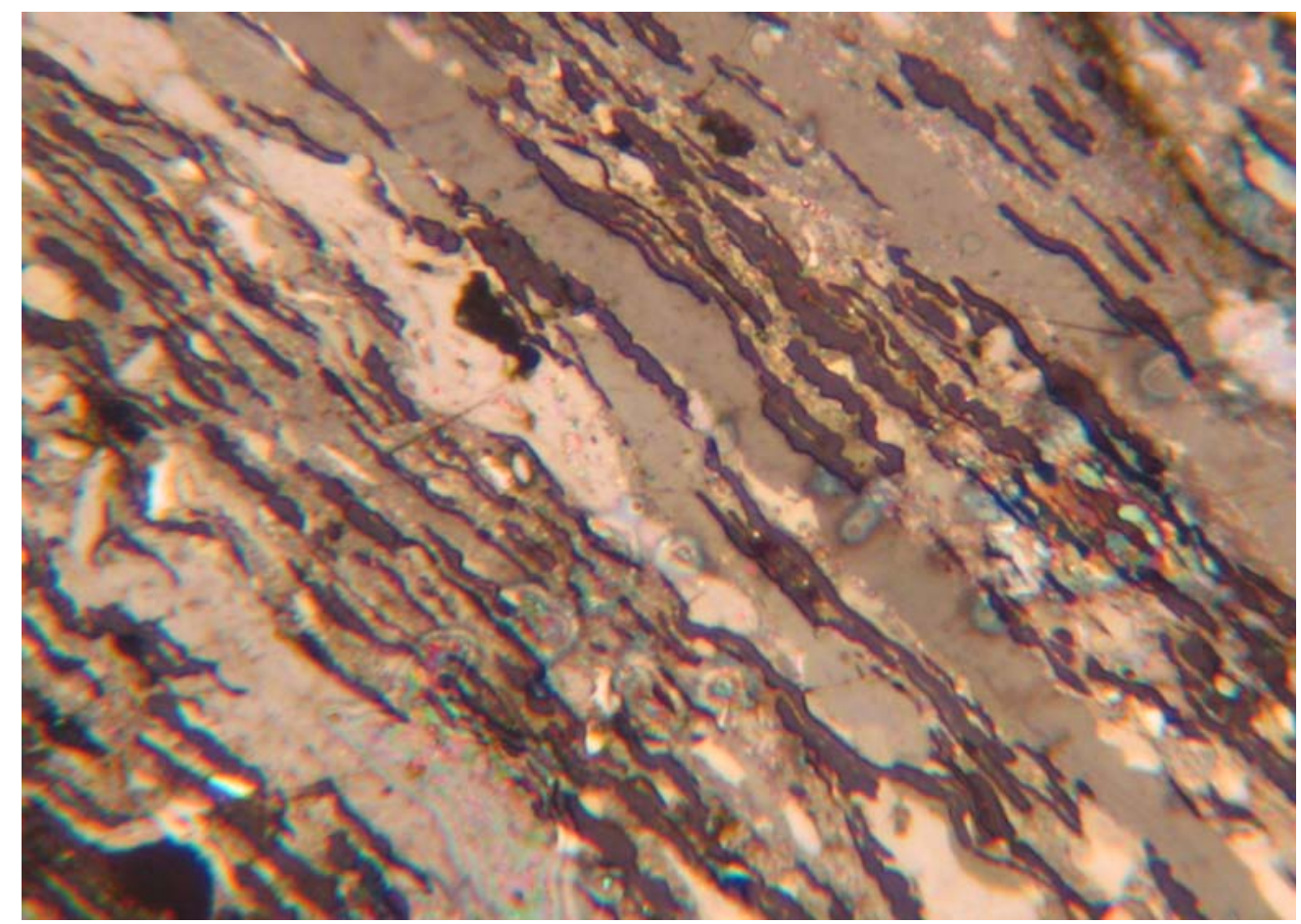

Figure 13. Trimaceral region in the low sorption region. The dark wavy material is liptinite (sporinite). The light material is intertinite. The gray material is vitrinite. 


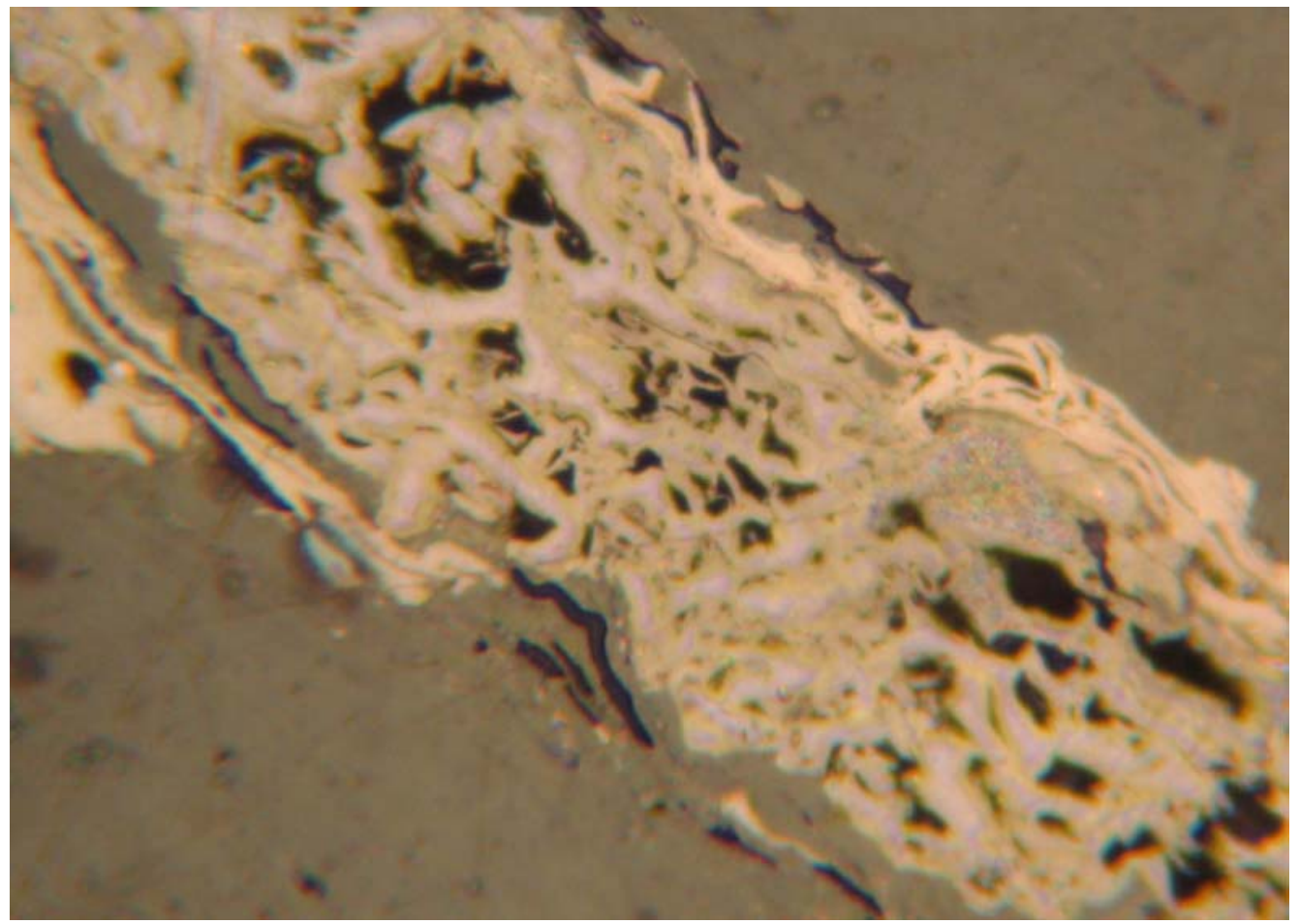

Figure 14. Inertinite (fusinite) band surrounded by vitrinite bands.

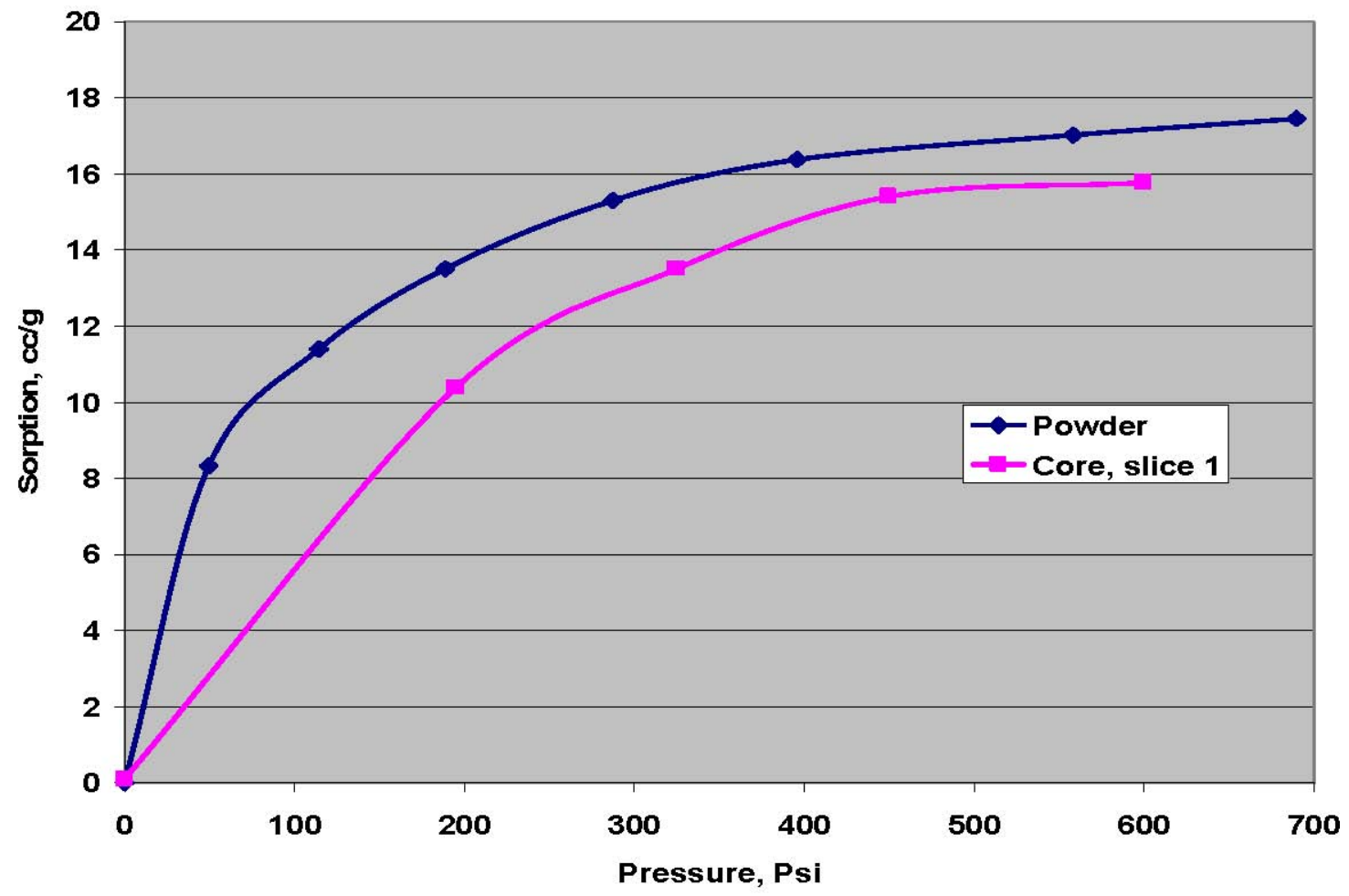

Figure 15. Comparison of sorption isotherms for the coal in powdered (unconfined) form and slice 1 of the confined core. 